\title{
A LEITURA LITERÁRIA NA SALA DE AULA
}

Clauber Ribeiro Cruz (IFRJ)

Resumo: Diante da área dos estudos das Letras, Artes e Linguística, temos como objetivo geral apresentar o processo e os resultados parciais da aplicação de uma experiência em sala de aula vinculada à leitura literária, realizada com os discentes do Ensino Médio Técnico da Rede Federal de Ensino do IFRJ. Essa proposta se embasa nos conceitos da teoria do Pós-Método, do professor Kumaravadivelu (2001); nos ideais defendidos pelo Professor e crítico literário Antonio Candido, em O direito à literatura (2017); e nos estudos do professor Rildo Cosson, em Letramento literário (2006). Entre os objetivos específicos, bem como sua metodologia, evidenciaremos o passo a passo de uma sequência didática básica, a qual leva em consideração o contexto sociocultural do público-alvo. Assim sendo, com a prática da educação literária, reiteramos a relevância de projetos pedagógicos autênticos, vinculados aos conceitos educacionais da era contemporânea.

Palavras-Chave: Educação Literária. Educação Pública; Pós-Método; Sala de Aula.

\begin{abstract}
: this texts aims to show the process and some results of an experience in the classroom, related to the literary reading. The approach used belongs to the Language, Arts and Linguistic major area of studies. The methodology was accomplished with the students in the Brazilian Federal Public Education System (IFRJ). Futhermore, this approach is based on the Post-Method Pedagogy, developed by the professor Kumaravadivelu (2001); and in the ideals supported by the professor Antonio Candido, in O direito à literatura (2017); and in the studies of the Professor Rildo Cosson, Letramento literário (2006). Among the specific goals, such as the methodology, we will highlight the procedures of a basic teaching method, which takes into consideration the sociocultural context of the target group. Thus, through this literary education approach, we intend to show the relevance of authentic pedagogical projects, concerned to the education concepts of the contemporary era.
\end{abstract}

Keywords: Literary Education. Public education. Post-Method Pedagogy. Classroom. 


\section{INTRODUÇÃO}

A literatura corresponde a uma necessidade universal que deve ser satisfeita sob pena de mutilar a personalidade, porque pelo fato de dar forma aos sentimentos e à visão do mundo ela nos organiza, nos liberta do caos e portanto nos humaniza. Negar a fruição da literatura é mutilar nossa humanidade. Antonio Candido (2017)

$\mathrm{O}$ assunto abordado neste texto fundamenta-se por meio da realização das aulas de Língua Portuguesa/Literaturas desenvolvidas com as turmas do primeiro ano do Ensino Médio Integrado ao Técnico em Guia de Turismo do Instituto Federal de Educação, Ciência e Tecnologia do Rio de Janeiro (IFRJ), no campus Avançado Resende.

Além disso, a proposta didática embasa-se nos conceitos pragmáticos e teóricos da Pedagogia do Pós-Método e, também, leva em consideração os ideais defendidos pelo Professores Rildo Cosson, em Letramento literário (2006), e de Antonio Candido, no seu estudo O Direito à Literatura (2017), tal como a epígrafe acima propõe: negar o direito à literatura aos nossos educandos, é refutar o direito à humanização por meio da fabulação.

De acordo com Antonio Candido (2017, p.176), o fenômeno literário surge como manifestação universal de todos os homens em todos os tempos, tendo em vista que não há um povo e não há homem que possa viver sem ela, isto é, sem 
a possibilidade de entrar em contato com alguma forma de fabulação, haja vista que todas as noites somos entregues ao universo poético por meio dos nossos sonhos:

O sonho assegura durante 0 sono a presença indispensável deste universo, independentemente da nossa vontade. E durante a vigília a criação ficcional ou poética, que é a mola da literatura em todos os seus níveis e modalidades, está presente em cada um de nós, analfabeto ou erudito, como anedota, causo, história em quadrinhos, noticiário policial, canção popular, moda de viola, samba carnavalesco.

(CANDIDO, 2017, p.176-177)

Nesse sentido, se ninguém pode passar vinte e quatro horas sem ter contato com o universo da fantasia, podemos dizer que a literatura é uma necessidade de todos os seres humanos e, por sua vez, apresenta-se como um direito que precisa ser satisfeito.

Assim sendo, esta sequência didática originou-se a partir desses ideais, com a finalidade de conduzir os diversos estudantes do campus ao contato essencial com o texto literário, o qual contém o poder humanizador da literatura, isto é, a capacidade de provocar o exercício do saber, da reflexão, da empatia com o próximo, da capacidade de penetrar nos problemas da vida, do senso da beleza, da percepção da complexidade dos seres e do mundo, em 
outras palavras: "[...] A literatura desenvolve em nós a quota de humanidade na medida em que nos torna mais compreensivos e abertos para a natureza, a sociedade, 0 semelhante" (CANDIDO, 2017, p.182).

Destarte, nós, professores, diante de grupos de educandos cada vez mais interconectados com as ferramentas da era digital e muitas vezes distantes do universo da leitura (literária), somos cotidianamente desafiados a reelaborar nossas metodologias, a fim de buscar por estratégias que sejam capazes de atender às expectativas e necessidades dos discentes com os quais trabalhamos. Desse modo, não podemos perder de vista que a obra literária pode ser uma grande aliada nesse processo, visto que nos torna aptos a ordenar a nossa mente e sentimentos; e, consequentemente, mais capazes de organizar a visão que temos do mundo (CANDIDO, 2017, p.179).

Deste modo, partimos do princípio de que antes de estabelecer o contato com as produções literárias, é preciso ouvir os estudantes, diagnosticar o perfil leitor, os seus desejos, sonhos e objetivos, ou mesmo incitar esses caminhos. Assim, podemos estabelecer um espaço mais igualitário e contextualizado para a realização do trabalho, oportunizando a experiência com os diversos tipos de bens culturais valorizados pela sociedade contemporânea: 
Nas sociedades que procuram estabelecer regimes igualitários, o pressuposto é que todos devem ter a possibilidade de passar dos níveis populares para os níveis eruditos como consequência normal da transformação de estrutura, prevendo-se a elevação sensível da capacidade de cada um graças à aquisição cada vez maior de conhecimentos e experiências.

(CANDIDO, 2017, p.190-191)

Assim, de modo a alcançar o referido ideal, as teorias do campo educacional têm sido (re)formuladas com o intuito de (re)conectarem-se com o panorama corrente de ensino, visto que, com o advento da Internet, as fronteiras culturais, linguísticas e sociais têm alçando patamares globais. Desta maneira, atualmente, a concepção de letramento literário rompeu com os muros das relações locais e ampliouse às conectividades internacionais. Em outras palavras, as diversas relações linguísticas e as diferenças culturais globalizadas devem ser parte fundamental da formação de um currículo escolar contemporâneo.

Portanto, a Teoria do Pós-Método tem figurado entre as concepções de ensino do século XXI. Essa abordagem foi elaborada pelo professor Kumaravadivelu, em seu estudo Toward a Postmethod Pedagogy (2001), no qual desenvolve as ideias basilares dos procedimentos teórico-práticos da proposta, a qual se apresenta com eficiência à era das intercomunicações e relações voláteis da atualidade. 
A Pedagogia do Pós-Método é caracterizada por buscar estratégias efetivas de ensino de línguas considerando a atuação prática e o papel autêntico dos discentes em ações significativas, traçando uma intersecção entre o mundo do conhecimento do educando com partes do universo do saber ainda desconhecidos. Isto é, a partir do que o aluno já traz como repertório sociocultural, estabelecese um caminho intercruzado para as áreas que o discente desconhece, revelando-o distintas perspectivas em direção ao pensamento crítico. Desse modo, os materiais didáticos e os procedimentos pedagógicos são (re)elaborados para alcançar essa meta.

No entanto, ainda segundo Kumaravadivelu (2001, p.538), o termo Pós-Método não está vinculado somente com a formulação de estratégias de procedimentos pedagógicos e desenvolvimento de materiais, mas também com a sua integração aos contextos históricos, políticos e socioculturais, os quais agem (in)diretamente na formação linguística dos educandos, tal como na estruturação da concepção educacional do tempo em que se vive.

Ademais, de modo a atingir resultados favoráveis à aplicação desta abordagem, a pedagogia do Pós-Método passa por três etapas essenciais, são elas: "a pedagogia da particularidade", a "pedagogia da prática" e a "pedagogia da possibilidade". 
A primeira delas considera um grupo específico de professores, lidando com um grupo particular de educandos, em busca de um quadro de metas inserido em um contexto integrado a uma situação sociocultural, também, específica. Isto é, para a realização dessa parte, é preciso que o docente se envolva com o ambiente sociocultural vivido pelos discentes para que, assim, estabeleça metas e estratégias que sejam autênticas ao público-alvo.

Além do mais, todo o processo pedagógico precisa, primeiramente, ser local, ou seja, é necessário olhar para a realidade dos discentes com os quais se trabalha, porque ignorar essa relação é menosprezar experiências de vida, as quais são fundamentais para o exercício ético da educação.

Já a segunda está relacionada à teoria elaborada pelo próprio professor, em outras palavras, a teoria da prática, a qual é gerada a partir da ação docente. Usualmente, o pensamento educacional acadêmico não prevê a reflexão sobre a aplicação de conceitos teóricos em distintas realidades socioculturais. Com isso, corroboram-se resultados desfavoráveis relacionados ao ensino. Com base na formulação de uma teoria a partir da prática, o docente tem a oportunidade de aplicar conceitos metodológicos com base na experiência real de seu trabalho. 
Assim sendo, ao levar esse panorama em consideração, teríamos uma teoria pedagógica com resultados favoráveis à prática docente-discente e, como resultado, o desenvolvimento autônomo dos educandos, já que o conhecimento acadêmico somar-se-ia com a teoria do professor formulada a partir da análise do espaço sociocultural vivido por seus estudantes.

A terceira, por sua vez, está integrada ao empoderamento dos educandos, de modo a considerá-los protagonistas de suas caminhadas identitárias rumo ao (auto)conhecimento, isso por meio da construção do saber com base nas experiências e práticas sociais. Ou seja, há uma relação direta entre identidade e transformação social; língua, cultura e formação educacional.

Diante desse panorama exposto, neste artigo, temos como objetivo geral apresentar os resultados parciais da aplicação de uma experiência vinculada à leitura literária em sala de aula, realizada com os discentes do primeiro ano do Ensino Médio Técnico Público Federal. Vale salientar que, apesar de ter sido desenvolvida com este público-alvo, ela pode ser adaptada para diversas situações e níveis de ensino, inclusive no que concerne aos estudos pedagógicos na formação superior de docentes. 
Já em relação aos os objetivos específicos, bem como sua metodologia, evidenciaremos o passo a passo dos procedimentos realizados, de modo a elaborarmos uma sequência didática que visa à educação literária.

\section{DESENVOLVIMENTO}

A literatura nos diz o que somos e nos incentiva a desejar e a expressar o mundo por nós mesmos. $E$ isso se dá porque a literatura é uma experiência a ser realizada. [...] No exercício da literatura, podemos ser outros, podemos viver como outros, podemos romper os limites do tempo e do espaço de nossa experiência e, ainda assim, sermos nós mesmos. É por isso que interiorizamos com mais intensidade as verdades dadas pela poesia e pela ficção. (COSSON, 2006, p.17)

Com o objetivo de incentivar os discentes a lerem mais textos literários e, consequentemente, melhorarem suas produções de texto e pensamento crítico, decidimos montar uma sequência didática experimental, haja vista que o seu planejamento deve observar a efetividade ou não da proposta. Diante disso, uma reformulação é normalmente necessária para o aprimoramento da ideia, uma vez que estamos inseridos em um eterno processo de autoaprendizagem.

Ao levar em consideração que o ato da leitura pode ser uma atividade solitária, mas que nunca deixa de ser solidária, a proposta desta atividade pretende criar condições para 
que o universo das palavras potencializadas pela poética unam-se com o mundo do aluno e de sua sociedade.

Após cerca de dois meses de trabalho com as turmas, diagnosticamos parte do contexto sociocultural dos envolvidos e fizemos o levantamento do repertório de leitura dos discentes. Com base nisso, foi feita uma coletânea de textos que seriam lidos e trabalhados ao longo do bimestre. Observe que nesse quesito foi aplicado o conceito da "pedagogia da particularidade", ou seja, primeiro descobrimos qual o contexto sociocultural dos discentes com os quais trabalhamos antes de escolhermos o material a ser aplicado. Com isso, a efetividade da proposta é mais direcionada e as chances de torná-la significativa são maiores.

Com a finalidade de montar um plano de ensino progressivo, isto é, de acordo com a evolução do grupo, novas configurações procedimentais surgiriam. Assim, decidimos começar com gêneros textuais de extensão mais breve, como contos, crônicas e poemas, para aguçar o desejo pela leitura. Caso o resultado alcançasse a nossa meta inicial, novas reformulações seriam articuladas com o intuito de ampliar a complexidade do fenômeno em estudo:

Crescemos como leitores quando somos desafiados por leituras progressivamente 
mais complexas. Portanto, é papel do professor partir daquilo que o aluno já conhece para aquilo que ele desconhece, a fim de se proporcionar o crescimento do leitor por meio da ampliação dos seus horizontes de leitura. (COSSON, 2006, p.35)

Entre os textos escolhidos para este momento, apresentam-se: Olhos d'água, de Conceição Evaristo; $A$ bola e Da timidez, de Luis Fernando Verissimo; A fronteira de asfalto, de Luandino Vieira; A menina sem palavra, de Mia Couto; e poemas dos escritores Fernando Pessoa e Mário Quintana. Conforme a resposta das primeiras aulas, decidiríamos se manteríamos ou não os textos sugeridos.

Dividimos os textos em 3 blocos, no primeiro deles, havia as produções da escritora Conceição Evaristo e do escritor Luis Verissimo; o segundo, os poemas de Fernando Pessoa e Mário Quintana; e no terceiro, os contos de Mia Couto e Luandino Vieira.

Primeiramente, com a leitura dos textosiniciais, explicamos aos discentes o que iríamos fazer e como proceder. De uma forma entusiasmada, antecipamos algumas passagens do enredo das narrativas e fizemos uma breve apresentação dos autores. Assim, os alunos já teriam uma leitura prévia feita pelo professor, e claro, sem disponibilizar nenhum spoiler, já que o objetivo é mantê-los motivados. 
Essa seria, portanto, a motivação de nossa sequência básica, também conhecida como fase da pré-leitura, parte esta muito importante, uma vez que é nela que preparamos os educandos para entrarem no texto e darem significado à leitura: "[...] O sucesso inicial do encontro do leitor com a obra depende de boa motivação" (COSSON, 2006, p.54).

Após esse momento, estipulamos uma semana para os alunos realizarem a leitura dos textos sugeridos. Assim, com o objetivo de auxiliá-los neste primeiro momento, elaboramos uma ficha de leitura para que os estudantes criassem o hábito de tomarem notas, haja vista que esse procedimento poderia ajudá-los na hora do debate.

Perceba que a ficha de leitura é um elemento que não limita a recepção dos textos, pelo contrário, cada educando mantém a sua visão crítica sobre o que foi lido. Ademais, com seria a primeira vez que realizaríamos esse modelo de atividade, decidimos auxiliar os discentes na leitura e na organização de suas ideias por meio da escrita. Em momentos posteriores, deixamos os estudantes mais à vontade nesse quesito, já que que a partir disso, prevíamos um conduta mais autônoma. Observem o modelo a seguir: 


\section{Ficha de Leitura}

1) Referência da obra: indicar aqui a referência completa de acordo com a ABNT (Associação Brasileira de Normas Técnicas). Exemplo: Cervantes, Miguel de. Dom Quixote de la Mancha. Trad. de Almir de Andrade, Milton Amado. 2. ed. Rio de Janeiro: Nova Fronteira, 2016.

2) Síntese da obra: apresentar de forma objetiva o tema do texto lido. Sugere-se realizar um resumo com as próprias palavras. Para tanto, a síntese deve descrever o conteúdo sucintamente.

3) Avaliação crítica: redija uma avaliação crítica do texto. Ou seja, posicione-se diante da leitura, destacando insights, possíveis links - afinidades e contrapontos - com outros autores e sua relação com a sociedade; destaque questões relevantes do texto para o debate, perspectivas que o tema abordado pode lançar para a reflexão do texto (isto é, o tema pensado para além do que o texto desenvolve). Por fim, elabore uma avaliação pessoal do texto lido.

Em relação ao item 1, referência da obra, notamos a importância do estudante perceber a organização catalográfica do título, elemento relevante para pesquisas e indicações da edição. No item 2, síntese da obra, neste momento, buscamos que os discentes façam o exercício da 
concisão, notando os elementos-chave da narrativa. Já no item 3, avaliação crítica, almejamos que o educando perceba a relação entre o contexto e a sociedade, ou seja, de que modo o enredo está interligado com as ideias vinculadas ao seu universo de convívio.

Nesse item, também exercitamos o conceito da "pedagogia da possibilidade", no qual o discente constrói a suas percepções críticas de leitura de acordo com o seu repertório, motivadas a partir das questões vinculadas a sua identidade, uma vez que o processo de humanização da fabulação pode agir sobre a sua personalidade.

Após a parte de motivação e organização da impressões da leitura, para o dia da realização da atividade, preparamos um espaço convidativo, demos o nome a este momento de Roda Literária, na qual, à moda dos griots, os contadores de histórias africanas, sentaríamos em roda para apreciar boas narrativas poéticas repleta de visões humanizadas pelo poder das letras.

Assim sendo, sentamos no chão, mudando a configuração clássica da sala; outras vezes, ao ar-livre, sob uma árvore; colocamos uma música de fundo, distribuímos alguns chocolates e demos início à atividade proposta. Perceba que além da motivação inicial e a organização da leitura, 
foi preparada uma atmosfera para este instante, a fim de proporcionar aos educandos um momento sensível e agradável à fruição textual.

Essa organização tem relação com a "pedagogia da prática", ou seja, a soma da teoria acadêmica com a teoria do professor. Após observar e conhecer melhor o grupo de discentes, esta sequência básica foi traçada de acordo com o perfil de educandos do espaço escolar de trabalho. Desta forma, as ações pragmáticas e teóricas aplicaram-se de modo mais contextual. Vale ressaltar que cada grupo escolar deve ser avaliado de acordo com as vivências entre docente e discente. Ao levar isso em consideração, as abordagens e metodologias podem ser elaboradas de maneira mais efetiva.

A fim de apresentar as obras e seus respectivos autores, fizemos uma breve introdução dos títulos e da biografia dos autores. Apesar de importante, salientamos que esse momento não deve ser demorado, visto que o elemento principal neste dia é o texto literário. Caso os discentes se interessem pelos autores e suas obras, vale a pena fazer indicações de leitura e aprofundar o momento com pesquisas, ou mesmo preparar uma outra aula para discutirem essas informações.

Tomamos o cuidado, também, de trazer os títulos originais das obras, mostrando os livros e suas edições. Assim, 
passando de mãos em mãos, os discentes materializaram os títulos e se entusiasmaram a continuarem a leitura completa posteriormente. Ao fim da atividade, normalmente alguns educandos pedem para lerem os livros na íntegra. Sem hesitar, passamos as obras e sentimos que o trabalho vai ganhando delineamento positivo.

Na sequência dessa etapa, vamos à terceira fase da sequência didática: a interpretação: “[...] A interpretação é feita com o que somos no momento da leitura. Por isso, por mais pessoal e íntimo que esse momento interno possa parecer a cada leitor, ele continua sendo um ato social" (COSSON, 2006, p.65). Nesse sentido, acreditamos que a realização da obra se completa quando se encontra com o leitor, tornando o ato social da leitura um instrumento de grande relevância para relação entre literatura e sociedade.

Com isso, com as partes divididas pela ficha de leitura sugerida como procedimento da dinâmica, recuperamos primeiramente o resumo da narrativa para nos apropriarmos dos fatos narrados. Na sequência, distribuímos um material que continha as características essenciais do gênero conto e crônica, visto que seria um momento oportuno para refletirmos não somente acerca do conteúdo, mas também sobre a forma. 
Assim, conforme o desenvolvimento das impressões de leitura acontecia, os fatos eram guiados, na medida do possível, pelas seguintes categorias narrativas: motivo inicial, objeto de desejo, narrador, personagens, ação, tempo, espaço, discurso, conflito, clímax e desfecho.

Ao final da atividade, por mais que isso já tenha acontecido indiretamente, passamos às visões críticas sobre a narrativa e, conforme as ideias surgiam, os próprios discentes iam realizando ora argumentos a favor ora contra o posicionamento um dos outros, não perdendo de vista o mote central do enredo. Nesse momento, é importante o papel mediador do docente, o qual, com equilíbrio, tem que ter a sensibilidade de aprofundar os assuntos, interligar ideias, na medida em que os educandos lançam propostas que podem reforçar a temática.

A sequência didática foi repetida mais duas vezes no semestre, seguindo o roteiro dos textos proposto nos 3 blocos de leitura. Nas novas aplicações, sempre fazíamos uma reflexão sobre o método de trabalho já utilizado, ou seja, o que funcionou mais e menos na primeira abordagem. Com esse procedimento, melhoramos cada vez mais a relação entre metodologia e prática. A própria realização da mesma atividade em turmas diferentes já foi executada com procedimentos adaptados ao perfil da classe. 
Quando trabalhamos com os poemas, após a parte didática de pré-leitura, leitura e pós-leitura, ao fim, propusemos a criação de poemas inspirados nas criações poéticas de Fernando Pessoa, Autopsicografia, e de Mário Quintana, Poema. De modo a incentivá-los ainda mais nesse processo de escrita criativa, projetamos a confecção de um livro de poemas da turma, o qual seria impresso e espalhado pelos diversos espaços do campus. A produção ganhou este nome: Se(r)mentes Poéticas. Vejamos a capa a seguir:

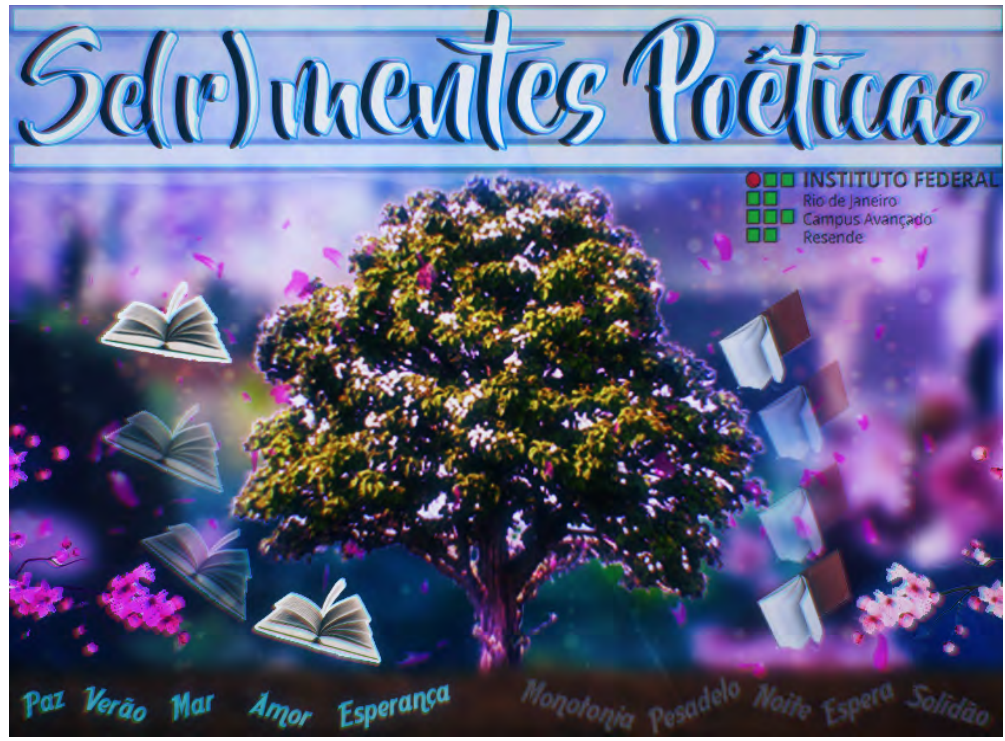

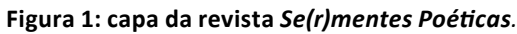

A partir do convite do professor, a capa foi feita por um dos estudantes do campus. Ainda nessa edição, foi feito um prefácio que salientou a construção do material e as 
temática das criações. Ademais, confeccionamos algumas cópias que circularam entre os discentes e deixamos alguns exemplares pelos diversos espaços do Instituto. Acreditamos que esse tipo de procedimento instiga e valoriza os trabalhos dos discentes.

Devido ao sucesso da primeira edição da revista literária, resultado do trabalho dessa sequência didática com as Rodas de Leitura, em uma parceria com o docente da disciplina de história, começamos a elaborar a segunda edição. Dessa vez, escolhemos como temática a desconstrução de estereótipos acerca do continente africano. Trabalhamos nas aulas de literatura algumas narrativas africanas de língua portuguesa; enquanto nas de história foi feita uma abordagem pelo viés histórico.

Como um dos resultados, belíssimos textos foram escritos pelos discentes. Apesar dos trabalhos terem culminado em produções escritas, sabendo da relevância do gênero oral, em nossa III Semana Acadêmica realizamos uma atividade aberta à comunidade externa, na qual os estudantes apresentaram suas narrativas em um formato de "contação de histórias". No total, 15 grupos fizeram performances inesquecíveis em uma bela tarde de sol sob a sombra de uma árvore. Vejamos a capa da segunda edição: 


\section{Se(r)Mentes Paéticas}

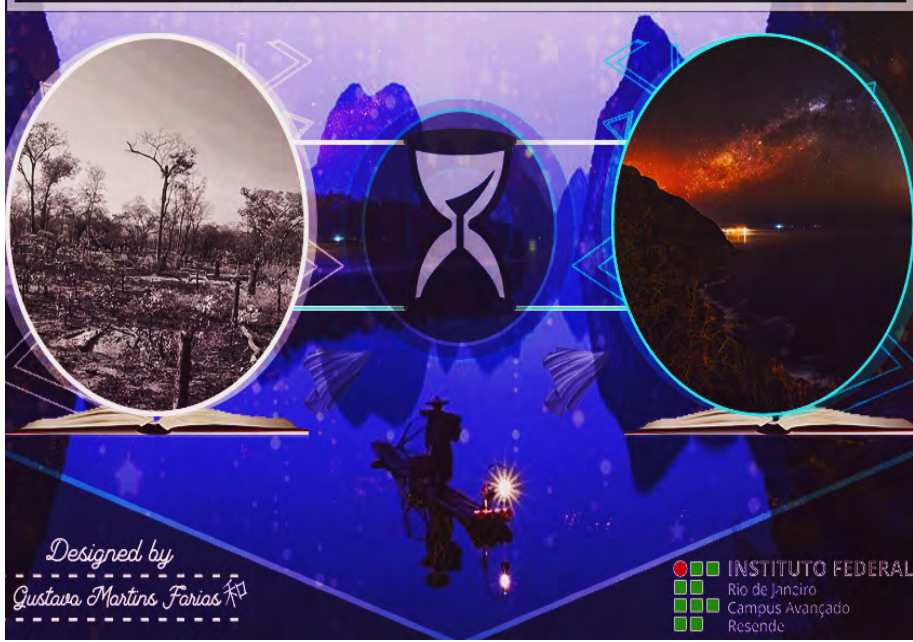

Figura 2: capa da revista Se(r)mentes Poéticas.

Como um segundo passo a ser seguido, isto é, a escrita, é muito importante que se dê um local para a criação dos textos, ou seja, os discentes precisam entender por que vão escrever, qual o propósito dessa produção. Além do mais, sugerimos que isso seja feito concomitante ao trabalho inicial de motivação da leitura. No nosso caso, pelo fato de publicarmos os trabalhos em formato de revista literária, ou mesmo na exposição dos escritos pelo campus, fez com que os textos fossem revalorizados, possibilitando mais significado aos estudantes, os quais teriam suas criações apreciadas pela comunidade escolar.

Por fim, frisamos a importância da montagem de planos de aula que tenham como alvo o perfil de discentes com 
os quais se trabalha e, com base nisso, a construção de abordagens integradas a esse prognóstico. Ademais, é necessário levar em consideração o contexto social, cultural, linguístico e histórico vigentes para que a conexão entre local e global seja efetivada significativamente. E como acreditamos no poder transformador da educação literária, a seleção de textos autênticos e a motivação da abordagem antes e durante a dinâmica são cruciais para o sucesso do trabalho.

\section{CONCLUSÃO}

Iniciamos a nossa reflexão defendendo a tese de que a leitura literária tem o poder humanizador provocado pela fabulação. Nesse sentido, após a sequência didática aplicada, mantemos e reafirmamos o nosso posicionamento, já que os resultados positivos foram mais do que (trans)formadores.

Vale salientar que a experiência com a literatura não corrompe, nem edifica; porém, nos humaniza no sentido profundo, porque nos faz viver (CANDIDO, 2017, p.178). E foi exatamente isso que ocorreu nesses momentos, vivenciamos o universo literário em contato com a realidade dos nossos educandos, deixando as experiência provocada pelo texto poético se manifestar a partir da relação entre o texto e o estudante. 
Desse modo, salientamos ser crucial levar em consideração o perfil local dos estudantes, ou seja, desenvolver um diagnóstico prévio antes da elaboração dos procedimentos pedagógicos. Nesse momento, precisamos ouvi-los atentamente e descobrirmos os pontos temáticos que os motivam. A partir disso, integramos os nossos projetos já contextualizados com a realidade dos discentes.

Por sua vez, observamos que a abordagem do Pós-Método busca por estratégias de ensino que atendam cada vez mais a realidade de nossos estudantes. Nesse sentido, o que nos propõem o estudo de Kumaravadivelu não é a busca por um método ideal, mas sim o que está além do método, ou seja, o "não método". Para isso, é preciso avaliar com propriedade o repertório dos discentes com os quais os docentes trabalham e, consequentemente, elaborar planos de ensino autênticos. Assim, objetiva-se impulsionar o mundo do conhecimento dos educandos para um universo ainda não desbravado.

O desafio, caros professores/leitores, é muito grande, sabemos disso, visto que em diversas escolas espalhadas pelo nosso país somos obrigados a trabalhar com materiais já prontos, com seus conteúdos maçantes e, muitas vezes, em desencontro com a realidade dos alunos e com as nossas percepções educacionais, sem contar na pressão de calendários acadêmicos que atrapalham o desenvolvimento 
das atividades. Contudo, a luta por um país de base educacional transformadora passa pela desconstrução de formas engessadas e por transgressões pedagógicas. Desafiem-se!

Após aplicada essa proposta de ensino, nossos alunos, além de apropriarem-se do conteúdo trabalhado, ainda se aproximaram mais do docente, o que deixou o ambiente mais afetivo e produtivo. As habilidades da leitura, escrita e oralidade foram melhoradas qualitativamente. Sabemos que há muito a que se aprimorar ainda, mas o passo inicial foi dado com efetividade, estudo, paixão e disciplina.

Embora o procedimento não tenha alcançado a todos, a sua maioria foi contemplada e exposta positivamente ao universo das Letras. O caminho do fazer pedagógico trilha esses desafios: ora temos bons resultados, ora não. É um eterno percurso do tecer a manhã, como já nos disse o poeta João Cabral de Melo Neto.

Ao final das atividades, os risos, os olhares curiosos e perguntas como: quando teremos a Roda Literária novamente, nos dão a certeza de que estamos no rumo certo e, também, nos alimentam de esperança para continuar a acreditar que a formação educacional pode mudar os percursos obscuros de um país muitas vezes cego de suas escolhas. Que a sala de aula seja sempre um espaço de (trans)formação, inovação, paixão e criação. 


\section{REFERÊNCIAS}

ARIKAN, Arda (2006). "Postmethod Condition and its Implications for English Language Teacher Education". Journal of Language and Linguistic Studies. 2(1), Abr, 1-11.

B. KUMARAVADIVELU (2001). "Toward a postmethod pedagogy". Tesol Quartely. 35(4), Winter, San José State University San José, California, United States, 537-560.

CANDIDO, Antonio (2017). O direito à literatura". In: Vários Escritos. Rio de Janeiro: Ouro sobre Azul, p.171-193.

COSSON, Rildo (2006). Letramento literário: teoria e prática. São Paulo: Contexto.

DOLZ, Joaquim; SCHNEUWLY, Bernard (2004). “Gêneros e progressão em expressão oral e escrita - elementos para reflexões sobre uma experiência suiça (francófona)". In: Gêneros orais e escritos na escola. Roxane Rojo e Glaís Sales Cordeiro (Trad.). (Orgs.). Campinas: Mercado de Letras.

ROJO, Roxane Helena Rodrigues; MOURA, Eduardo (Orgs.) (2012). Multiletramentos na escola. São Paulo: Parábola Editorial. Estratégias de Ensino; 29.

Clauber Ribeiro Cruz é Doutor (2018) e Mestre (2013) em Letras, com especialidade na área dos Estudos Literários: Literatura e Vida Social, pela Universidade Estadual Paulista Júlio de Mesquita Filho - UNESP/Assis. Graduado em Letras (2010), com Licenciatura Plena, Português/Inglês, pela mesma Universidade. Docente do Instituto Federal de Educação, Ciência e Tecnologia do Rio de Janeiro (IFRJ), Campus Avançado Resende, atuando nas seguintes áreas: Língua Portuguesa, Língua Inglesa e Literatura. ORCID iD: https://orcid.org/0000-0002-6465-7963 